\title{
Map Accuracy Standards
}

\section{Map Accuracy}

An inaccurate map is not a reliable map. " $\mathrm{X}$ " may mark the spot where the treasure is buried, but unless the seeker can locate " $\mathrm{X}$ " in relation to known landmarks, the map is not very useful.

The U.S. Geological Survey (USGS) publishes maps and other products at high levels of accuracy. Dependability is vital, for example, to engineers, highway officials, and land-use planners who use USGS topographic maps as basic planning tools.

As a result, the USGS makes every effort to achieve a high level of accuracy in all of its published products. An important aim of its accuracy control program is to meet the U.S. National Map Accuracy Standards.

\section{National Map Accuracy Standards}

To find methods of ensuring the accuracy of both location (the latitude and longitude of a point) and elevation (the altitude above sea level), the American Society for Photogrammetry and Remote Sensing - an organization actively involved in the science of making precise measurements from photographs (photogrammetry) and acquiring information from aerial photographs and satellite image data (remote sensing) — set up a committee in 1937 to draft accuracy specifications. Sparked by this work, agencies of the Federal Government, including the USGS, began their own inquiries and studies of map accuracy standards. In 1941, the U.S. Bureau of the Budget issued the "United States National Map Accuracy Standards," which applied to all Federal agencies that produce maps. The standards were revised several times, and the current version was issued in 1947. (The standards are printed on the reverse of this factsheet.)
As applied to the USGS 7.5-minute quadrangle topographic map, the horizontal accuracy standard requires that the positions of 90 percent of all points tested must be accurate within 1/50th of an inch ( 0.05 centimeters) on the map. At $1: 24,000$ scale, $1 / 50$ th of an inch is 40 feet (12.2 meters). The vertical accuracy standard requires that the elevation of 90 percent of all points tested must be correct within half of the contour interval. On a map with a contour interval of 10 feet, the map must correctly show 90 percent of all points tested within 5 feet (1.5 meters) of the actual elevation.

All maps produced by the USGS at 1:250,000 scale and larger are prepared by methods designed to meet these accuracy standards and carry the statement, "This map complies with National Map Accuracy Standards." Exceptions to this practice involve areas covered by dense woodland or obscured by fog or clouds; in those areas, aerial photographs cannot provide the detail needed for precise mapping. The USGS tests enough of its maps to ensure that the instruments and procedures the Survey uses are producing maps that meet the U.S. National Map Accuracy Standards.

\section{How the Survey Maintains Map Accuracy}

In 1958, the USGS began systematically testing the accuracy of its maps.

Presently, accuracy testing is performed on 10 percent of the mapping projects at each contour interval as a method of controlling overall quality. It is rare for a 7.5-minute map to fail the test, but this happens on occasion.

In testing a map, the USGS experts select 20 or more well-defined points; a typical point would be the intersection of two roads. Positions are established on the test points by field teams using sophisticated surveying techniques to determine positions from aerial photographs. Field survey methods are the only tests accepted for official accuracy testing. Positions must be obtained by surveys of a higher accuracy. Vertical tests are run separately to determine precise elevations. The mapped positions are checked against the field and (or) photogrammetrically determined positions results. If the map is accurate within the tolerances of the U.S. National Map Accuracy Standards, it is certified and published with the statement that it complies with those standards.

By such rigorous testing of some of its maps, the USGS is able to determine that its procedures for collecting map information ensure a high level of map accuracy.

\section{Factual Errors}

There are other kinds of errors in mapmaking. Names and symbols of features and classification of roads or woodlands are among the principal items that are subject to factual error. Mapmakers cannot apply a numerical value to this kind of information; they must rely on local sources for their information. Sometimes the local information is wrong. Sometimes names change or new names and features are added in an area. The USGS cartographers and editors check all maps thoroughly and, as a matter of professional pride, attempt to keep factual errors to a minimum.

"Errors" resulting from selection, generalization, and displacement are necessary results of mapping complex features at reduced scales. In congested areas, large buildings may be plotted to scale and the smaller buildings may have to be omitted; in showing buildings of irregular shape, small wings, bays, and projections usually are disregarded, and the outline is shown in general form. At 
map scale, it may not be possible to show each of several closely spaced linear features in its correct position. In such cases, one feature, such as a railroad, is positioned in its true location and others, such as parallel roads or rivers, are displaced the minimum amount necessary to make each symbol legible or are omitted to make the highest priority symbol legible.

\section{United States National Map Accuracy Standards}

With a view to the utmost economy and expedition in producing maps that fulfill not only the broad needs for standard or principal maps, but also the reasonable particular needs of individual agencies, the Federal Government has defined the following standards of accuracy for published maps:

1. Horizontal accuracy. For maps on publication scales larger than 1:20,000, not more than 10 percent of the points tested shall be in error by more than $1 / 30$ inch, measured on the publication scale; for maps on publication scales of 1:20,000 or smaller, 1/50 inch. These limits of accuracy shall apply to positions of well-defined points only. Well-defined points are those that are easily visible or recoverable on the ground, such as the following: monuments or markers, such as bench marks, property boundary monuments; intersections of roads and railroads; corners of large buildings or structures (or center points of small buildings). In general, what is well-defined will also be determined by what is plottable on the scale of the map with-in 1/100 inch. Thus, while the intersec-tion of two roads or property lines meeting at right angles would come within a sensible interpretation, identi-fication of the intersection of such lines meeting at an acute angle would not be practicable within 1/100 inch. Similarly, features not identifiable upon the ground within close limits are not to be considered as test points within the limits quoted, even though their positions may be scaled closely upon the map. This class would cover timber lines and soil boundaries. 2. Vertical accuracy, as applied to contour maps on all publication scales, shall be such that not more than 10 percent of the elevations tested shall be in error by more than one-half the contour interval. In checking elevations taken from the map, the apparent vertical error may be decreased by assuming a horizontal displacement within the permissible horizontal error for a map of that scale.

3. The accuracy of any map may be tested by comparing the positions of points whose locations or elevations are shown upon it with corresponding positions as determined by surveys of a higher accuracy. Tests shall be made by the producing agency, which shall also determine which of its maps are to be tested, and the extent of such testing.

4. Published maps meeting these accuracy requirements shall note this fact in their legends, as follows: "This map complies with National Map Accuracy Standards."

5. Published maps whose errors exceed those aforestated shall omit from their legends all mention of standard accuracy.

6. When a published map is a considerable enlargement of a map drawing (manuscript) or of a published map, that fact shall be stated in the legend. For example, "This map is an enlargement of a 1:20,000-scale map drawing," or "This map is an enlargement of a 1:24,000scale published map."

7. To facilitate ready interchange and use of basic information for map construction among all Federal mapmaking agencies, manuscript maps and published maps, wherever economically feasible and consistent with the use to which the map is to be put, shall conform to latitude and longitude boundaries, being 15 minutes of latitude and longitude, or 7.5 minutes, or 3.75 minutes in size.

\section{How To Obtain M ore Information}

For information on these and other USGS products and services, call 1-888-ASK-USGS, use the Ask.USGS fax service, which is available 24 hours a day at 703-648-4888, or visit the general interest publications Web site on mapping, geography, and related topics at http://mapping.usgs.gov/ www/products/mappubs.html.

Please visit the USGS home page at http://www.usgs.gov/. 